\title{
Separation of Hafnium from Zirconium and Their Deter- mination: Separation by Anion-Exchange
}

\author{
Lawrence A. Machlan and John L. Hague
}

\begin{abstract}
(August 2, 1962)
A procedure is described for the separation of hafnium from zirconium and their individual determination. The sample is dissolved in sulfuric and hydrofluoric acids and the hydrofluoric acid removed by fuming. After dilution with water, the solution is transferred to a column containing a strong quaternary amine anion-exchange resin (Dowex-1). The hafnium is eluted with diluted ( 3.5 percent by volume) sulfuric acid solution. Zirconium is removed by elution with 10 percent by volume sulfuric acid solution. The elements are precipitated with cupferron, ignited, and weighed as the oxides. For samples containing from twenty to eighty percent of zirconium, a second separation of the hafnium fraction using the column is necessary.
\end{abstract}

\section{Introduction}

The use of hafnium and zirconium in nuclear applications has made the separation and determination of the two an important problem. Because hafnium and zirconium are very difficult to distinguish chemically, they can, for many uses, be considered as one constituent. However, since hafnium and zirconium have very different nuclear properties, it is important to know the relative amounts of each present in materials used in the nuclear reactor field.

The difficulties encountered in separating hafnium from zirconium are well known $[6,7] .{ }^{1}$ It has been shown [1] that a separation of hafnium and zirconium can be obtained by anion-exchange in sulfuric acid solution.

The method described here has been used to determine hafnium and zirconium in mixtures of the two elements containing 80 percent or less of zirconium. Work is in progress to apply the method to materials containing more than 80 percent of zirconium.

The samples are dissolved in a sulfuric-hydrofluoric acid solution and the hydrofluoric acid is fumed off. The solution is diluted with water to 3.5 percent by volume of sulfuric acid and transferred to an anion-exchange column. The hafnium is eluted with a 3.5 percent sulfuric acid solution and then the zirconium is eluted with a 10 percent sulfuric acid solution. For samples containing more than about 20 percent of zirconium the hafnium fraction may contain some zirconium and a second separation using the column is necessary to insure complete separation. The hafnium and zirconium are precipitated with cupferron, ignited, and weighed as $\mathrm{HfO}_{2}$ and $\mathrm{ZrO}_{2}$.

The procedure for samples containing less than 20 percent of zirconium requires approximately 3 days to carry to completion, as about $12 \mathrm{hr}$ are required for the ion-exchange separation, and the

Figures in brackets indicate the literature references at the end of this paper. remaining time is required for dissolving the sample and for making the cupferron precipitations.

\section{Procedures}

\subsection{Ion-Exchange Columns}

The columns used in these experiments were constructed of polystyrene tubes approximately 12 in. long and 1 in. i.d. A simple column can be prepared from such tubing as follows: Insert a piece of polystyrene tubing 6 in. long, $3 / 16$ in. o.d. (with a $1 / 16$ in. wall) through a No. 5 waxed, rubber stopper, so that one end of the tubing is flush with the small end of the stopper. Attach another $6 \mathrm{in}$. length of the same tubing with a 2-in. length of Tygon $R$ tubing. Insert the rubber stopper into the bottom of the 1-in. i.d. tube. Attach a hose-cock clamp, used to control the flow rate, to the Tygon tubing. Columns suitable for continuous operation have previously been described for both glass [4] and plastic [5] assemblies, and these are convenient to use if a number of analyses are to be performed.

The anion-exchange resins used were Dowex-1, 200- to 400-mesh, having 8 percent of divinylbenzene crosslinkages. Experience during several years has shown that the mesh size of these resins may vary considerably from lot to lot. To select resin of suitable size, the material as received is air-dried, and sieved through a 270-mesh sieve. Most of the very fine material is removed from the fraction passing the 270-mesh sieve, as follows: Prepare a suspension of the resin in diluted ${ }^{2}$ hydrochloric acid $(1+19)$. The coarser fraction is allowed to settle for 10 to $15 \mathrm{~min}$, and the fines removed by decantation. Repeat the process several times, until most of the very fine material is removed.

Load the column with resin as follows: Cover the bottom of the column with a $1 / 4-$ to $3 / 8$-in. layer of acidresistant, polyvinyl chloride plastic "wool." Add

2 Diluted hydrochloric acid $(1+19)$ denotes 1 volume of concentrated hydrochloric acid, sp gr 1.18, diluted with 19 volumes of water. If no dilution is specified, the concentrated analytical reagent is meant. 
portions of the resin suspension so as to obtain a settled column of the resin that is $22 \mathrm{~cm}$ high. Wash the loaded column with approximately $100 \mathrm{ml}$ of diluted nitric acid $(1+9)$, and then perform several washing cycles by alternate additions of diluted hydrochloric acid $(1+9)$ and diluted hydrochloric acid $(3+1)$ to remove the remaining fines. Finally, wash the column with diluted sulfuric acid $(7+193)$, to convert the resin to the sulfate form. Approximately 350 to $400 \mathrm{ml}$ of sulfuric acid solution will be required, and the removal of the chloride can be followed by testing portions of the eluate with silver nitrate solution. The resin charge should not be allowed to become dry.

\subsection{Reagents}

Sulfuric acid solution (3.5 percent). - Add $70 \mathrm{ml}$ of sulfuric acid to $1,930 \mathrm{ml}$ of water, mix well, and cool to room temperature. This solution is referred to as 3.5 percent sulfuric acid solution in the procedure.

Cupferron solution $(60 \mathrm{~g}$ /liter $)$.-Dissolve $30 \mathrm{~g}$ of cupferron in $45 \mathrm{C} \mathrm{ml}$ of water, dilute to $500 \mathrm{ml}$, and filter through a dry filter. This solution should be cooled to about $5^{\circ} \mathrm{C}$ and prepared as needed, as the solution is not stable.

Cupferron wash solution.-Add $25 \mathrm{ml}$ of cupferron solution to $975 \mathrm{ml}$ of cold $\left(5{ }^{\circ} \mathrm{C}\right)$ diluted hydrochloric acid $(1+9)$. Prepare as needed.

\subsection{Procedure}

Transfer $0.5 \mathrm{~g}$ of the metal sample (accurately weighed) to a covered $25-\mathrm{ml}$ platinum crucible and add a suitable quantity $(14 \mathrm{ml}$ for samples containing less than 20 percent of zirconium, $21 \mathrm{ml}$ for samples containing from 20 to 60 percent of zirconium, and $28 \mathrm{ml}$, with some evaporation, for samples containing from 60 to 80 percent of zirconium) of diluted sulfuric acid $(1+3)$ and 5 to 6 drops of hydrofluoric acid. The sample will dissolve at room temperature. (II the sample is in the oxide form transfer an amount of sample equal to $0.5 \mathrm{~g}$ of hafnium and zirconium to the crucible, and add a suitable quantity (see above) of diluted sulfuric acid $(1+3)$ and 2 to $3 \mathrm{ml}$ of hydrofluoric acid. Heat gently on an air bath to dissolve.) After the sample dissolves, wash the cover with water and place the uncovered crucible on a sand or air bath. Evaporate the solution to fumes of sulfuric acid, cool, and wash down the walls of the crucible with water. Evaporate the solution to fumes again, cool, quantitatively transfer the solution to a 400-ml beaker, and add sufficient water to give a 3.5 percent sulfuric acid solution.

Transfer the solution of the sample in small increments (10 to $15 \mathrm{ml}$ ) to the equilibrated ion-exchange column. Wash the beaker four or five times with 5 -ml portions of the 3.5 percent sulfuric acid solution, transferring the washings to the column and allowing the solution to drain to the top of the resin each time. Finally wash down the sides of the column several times with a total of approximately $50 \mathrm{ml}$ of the same solution.

\section{a. For Samples Containing Less Than 20 Percent of Zirconium}

Discard the first $125 \mathrm{ml}^{3}$ of solution from the column. Continue adding the 3.5 percent sulfuric acid solution. Collect the second fraction of 550 $\mathrm{ml}$ (see footnote 3), containing the hafnium, in an $800-\mathrm{ml}$ beaker. Replace the beaker with a $600-\mathrm{ml}$ beaker to catch the zirconium fraction. Allow the solution to drain to the top of the resin and wash the sides of the column with 3 or 4 portions (a total of about $20 \mathrm{ml}$ ) of diluted sulfuric acid $(1+9)$, allowing the solution to drain to the top of the resin each time. Add a total of $250 \mathrm{ml}$ of diluted sulfuric acid $(1+9)$ and remove the beaker containing the zirconium fraction. Equilibrate the ion-exchange column for the next elution cycle by passing $400 \mathrm{ml}$ of 3.5 percent sulfuric acid solution through the resin and allowing the solution to drain to the top of the resin.

To the second fraction, containing the hafnium, add $65 \mathrm{ml}$ of hydrochloric acid. Cool to $5{ }^{\circ} \mathrm{C}$, and add slowly while stirring, $100 \mathrm{ml}$ of cupferron solution. Add a ball of paper pulp equivalent to about one 11-cm. filter paper, stir until the pulp is well dispersed, and allow the precipitate to settle. Filter through a double $7-\mathrm{cm}$ close-textured filter paper fitted to a Büchner funnel and precoated with some paper pulp. Transfer the precipitate to the funnel and wash, using $300 \mathrm{ml}$ of cupferron wash solution. Transfer the precipitate and paper to a weighed 25-ml platinum crucible, and ignite at a low temperature until the carbon is gone. Finally ignite to constant weight at $1,100{ }^{\circ} \mathrm{C}$, and weigh as hafnium dioxide.

To the third fraction, containing the zirconium, add $15 \mathrm{ml}$ of hydrochloric acid. Cool to $5^{\circ} \mathrm{C}$ and add slowly with stirring $50 \mathrm{ml}$ of cupferron solution. Add a ball of paper pulp equivalent to about one 11-cm filter paper, stir, and allow the precipitate to settle. Filter, wash, and ignite the zirconium precipitate as described for hafnium. Weigh the zirconium as the dioxide.

\section{b. For Samples Containing From 20 to 80 Percent of Zirconium}

Discard the first $125 \mathrm{ml}$ (see footnote 3) of solution from the column. Add a sufficien ${ }^{4}$ quantity of 3.5 percent sulfuric acid solution to elute all of the hafnium and some (10 to $50 \mathrm{mg}$ ) of the zirconium. Collect this second fraction in an $800-\mathrm{ml}$ beaker. Replace the beaker with a $600-\mathrm{ml}$ beaker and continue the elution of zirconium as described in section $2.3 \mathrm{a}$.

To the second fraction, containing the hafnium, and some zirconium, add $65 \mathrm{ml}$ of hydrochloric acid, and continue the procedure as described for hafnium in section $2.3 \mathrm{a}$, until the precipitate is ignited at low temperature. Reserve the oxides for a second separation using the column.

To the third fraction, containing zirconium, precipitate using 50 to $100 \mathrm{ml}$ of cupferron solution,

Each column must be calibrated to determine the volume of solution needed to elute the hafnium and zirconium. This is necessary because the resins and column loadings vary somewhat with different lots of resin.

${ }_{4}$ The quantity, approximately 500 to $600 \mathrm{ml}$, will depend on resin, column loading, and relative amounts of hafnium and zirconium. 
filter, and ignite as described for zirconium in section 2.3a. This is zirconium fraction one.

To the reserved oxides from the second fraction, add $14 \mathrm{ml}$ of diluted sulfuric acid $(1+3)$ and 1 to $2 \mathrm{ml}$ of hydrofluoric acid. Heat gently on an air bath to dissolve. After the oxides dissolve, wash the cover with water and place the uncovered crucible on a sand or air bath. Evaporate the solution to fumes of sulfuric acid, cool, and wash down the walls of the crucible with water. Evaporate the solution to fumes again, cool, quantitatively transfer the solution to a $250-\mathrm{ml}$ beaker, and dilute to $100 \mathrm{ml}$ with water.

Transfer the solution in small increments (10 to $15 \mathrm{ml}$ ) to the equilibrated ion-exchange column. Wash the beaker four or five times with 5-ml portions of the 3.5 percent sulfuric acid solution, transferring the washings to the column. Finally wash down the sides of the column several times with approximately $50 \mathrm{ml}$ of the same solution. Continue as described in section $2.3 \mathrm{a}$ to obtain the hafnium fraction and zirconium fraction two. Calculate the zirconium percentage from the sum of the two zirconium fractions and the hafnium percentage from the final hafnium fraction.

\section{Elution of Elements With Sulfuric Acid Solutions}

It has been shown previously [1] that hafnium can be separated from zirconium using 3.5 percent sulfuric acid solution to elute from resin having 8 percent of divinylbenzene crosslinkages having a maximum particle-sizing of about $50 \mu$ (passing through a 270 mesh sieve). To obtain more separation the height of the resin column was increased to $22 \mathrm{~cm}$. This separation, while not as great as other separations using ion-exchange $[2,3,8,9]$, is adequate if care is taken in setting up the columns, calibrating each column, and in preparing the solution used for the ion-exchange separation. The first three curves in figure 1 give the separation of hafnium from zirconi-
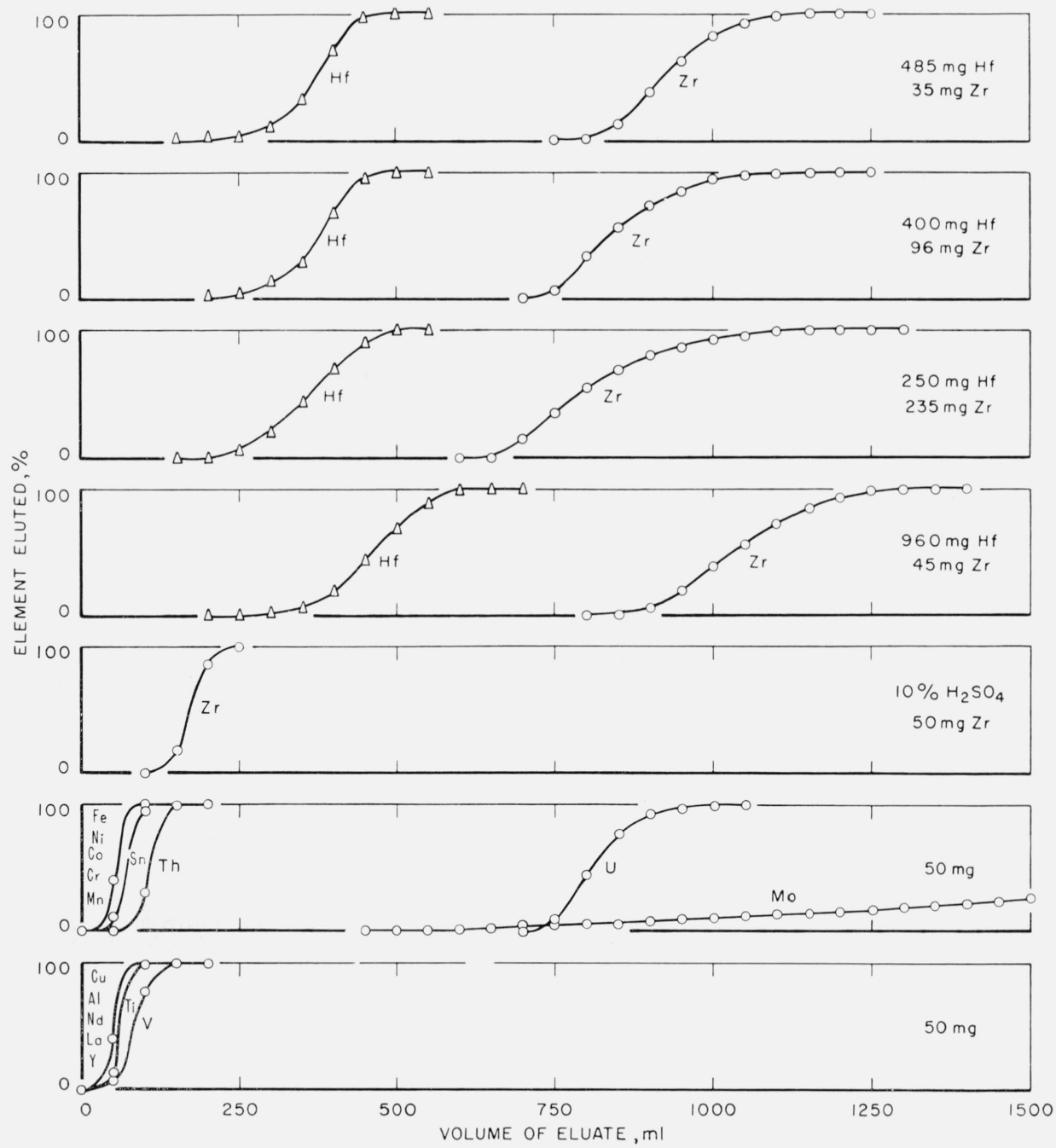

Frgure 1. Elution behavior of elements. 
um in $0.5 \mathrm{~g}$ samples of increasing zirconium-hafnium ratio by elution with 3.5 percent sulfuric acid solution. The fourth curve shows the separation obtained on a $1 \mathrm{~g}$ sample of hafnium metal by elution with 3.5 percent sulfuric acid solution. To obtain a reasonable volume of separation between the hafnium and the zirconium fractions, it is recommended that $0.5 \mathrm{~g}$ samples be used and that samples containing more than 20 percent of zirconium be determined by a double ion-exchange separation. To reduce the volume of solution needed to elute the zirconium, it was eluted with a 10 percent sulfuric acid solution. The fifth curve gives the zirconium elution curve in 10 percent sulfuric acid solution.

The last two curves give the elution characteristics of some other elements in 3.5 percent sulfuric acid solution. Iron (3), nickel (2), cobalt (2), chromium (3), manganese (2), copper (2), aluminum (3), neodymium (3), lanthanum (3), and yttrium (3) are eluted from the column without delay. Tin (4), thorium (4), titanium (4), and vanadium (5) are only slightly absorbed, all being eluted in 3 or 4 column volumes. Uranium (6) and molybdenum (6) are strongly absorbed. Elements that do not precipitate with cupferron, such as chromium, nickel, and cobalt, will not interfere with the determination of hafnium and zirconium by the recommended procedure. Elements that do precipitate with cupferron, such as iron, titanium, and molybdenum, would interfere in the recommended procedure. These elements are partially eluted into the discard fraction but to eliminate these interferences, the oxides can be redissolved and a mandelic acid or phosphate precipitation made.

\section{Results}

The results obtained by the recommended procedure on a series of synthetic oxide mixtures are given in table 1 . The first six experiments were done by the procedure recommended for samples containing less than 20 percent of zirconium. These values require little comment, being within the usual limits of gravimetric methods. Experiments 7 to 10 were done by the procedure recommended for samples containing írom 20 to 80 percent zirconium. These results show that for these compositions recoveries are within 2 to 5 parts per thousand. The oxides used in these experiments were obtained from previous ionexchange separations. Spectrographic examination of these oxides indicated less than 100 ppm cross contamination.

The results obtained on synthetic metal samples are given in table 2. The metals used were "reactor grade" metals. The zirconium was nearly hafniumfree and the hafnium (sample 1 in table 3 ) contained approximately 2.14 percent zirconium. The zirconium added was calculated from the zirconium in the hafnium metal and the zirconium metal added. Spectrographic examination of the recovered oxides indicated less than $100 \mathrm{ppm}$ zirconium in the hafnium fraction and less than 1 percent hafnium in the zirconium fraction.
The results obtained on two "reactor grade" hafnium metals is given in table 3 .

TABLE 1. Results of determinations of zirconium and hafnium by the recommended procedure in various synthetic oxide mixtures

\begin{tabular}{|c|c|c|c|c|c|c|}
\hline \multicolumn{4}{|c|}{ Hafnium oxide } & \multicolumn{3}{|c|}{ Zirconium oxide } \\
\hline $\begin{array}{l}\text { Experi- } \\
\text { ment }\end{array}$ & Added & Found & $\begin{array}{l}\text { Differ- } \\
\text { ence }\end{array}$ & Added & Found & $\begin{array}{l}\text { Differ- } \\
\text { ence }\end{array}$ \\
\hline $\begin{array}{l}1 \mathrm{a}- \\
2^{\mathrm{a}} \\
3^{\mathrm{a}} \\
4^{\mathrm{a}} \\
5^{\mathrm{a}} \\
6^{\mathrm{a}}\end{array}$ & $\begin{array}{c}m g \\
575.3 \\
574.9 \\
574.7 \\
476.8 \\
476.6 \\
476.2\end{array}$ & $\begin{array}{c}m g \\
574.9 \\
574.7 \\
574.6 \\
476.6 \\
476.3 \\
475.6\end{array}$ & $\begin{array}{c}m g \\
-0.4 \\
-.2 \\
-.1 \\
-.2 \\
-.3 \\
-.6\end{array}$ & $\begin{array}{r}m_{\mathrm{G}} \\
33.6 \\
33.9 \\
33.5 \\
133.2 \\
132.2 \\
127.2\end{array}$ & $\begin{array}{c}m g \\
33.7 \\
33.6 \\
33.4 \\
133.2 \\
132.0 \\
127.2\end{array}$ & $\begin{array}{r}m \zeta \\
+0.1 \\
-.3 \\
-.1 \\
.0 \\
-.2 \\
.0\end{array}$ \\
\hline $\begin{array}{r}7 \mathrm{r} \\
8^{\mathrm{b}}-\cdots \\
9^{\mathrm{b}} \cdots \\
10^{\mathrm{b}} \cdots\end{array}$ & $\begin{array}{l}294.9 \\
294.0 \\
146.0 \\
146.2\end{array}$ & $\begin{array}{l}295.6 \\
293.8 \\
146.2 \\
146.4\end{array}$ & $\begin{array}{r}+.7 \\
+.2 \\
+.2 \\
+.2\end{array}$ & $\begin{array}{l}334.1 \\
331.8 \\
502.1 \\
499.4\end{array}$ & $\begin{array}{l}335.3 \\
331.6 \\
502.8 \\
498.6\end{array}$ & $\begin{array}{r}+1.2 \\
-.2 \\
+.7 \\
-.8\end{array}$ \\
\hline
\end{tabular}

a Experiments"using the.procedure: "For samples containing less than 20 percent of zirconium."

b Experiments using the procedure: "For samples containing from 20 to 80 percent of zirconium."

TABLE 2. Results of determinations of zirconium and hafnium by the recommended procedure in synthetic metal samples

\begin{tabular}{|c|c|c|c|c|c|c|}
\hline \multicolumn{4}{|c|}{ Hafnium } & \multicolumn{3}{|c|}{ Zirconium } \\
\hline $\begin{array}{c}\text { Experi- } \\
\text { ment }\end{array}$ & Added & Found & $\begin{array}{l}\text { Differ- } \\
\text { ence }\end{array}$ & Added & Found & $\begin{array}{l}\text { Differ- } \\
\text { ence }\end{array}$ \\
\hline $\begin{array}{l}1 \\
2 \\
3\end{array}$ & $\begin{array}{c}m g \\
473.8 \\
464.2 \\
479.9\end{array}$ & $\begin{array}{c}m g \\
474.7 \\
465.2 \\
479.8\end{array}$ & $\begin{array}{c}m g \\
+0.9 \\
+1.0 \\
-0.1\end{array}$ & $\begin{array}{l}m g \\
36.2 \\
36.1 \\
28.5\end{array}$ & $\begin{array}{l}m g \\
35.6 \\
35.6 \\
28.6\end{array}$ & $\begin{array}{r}m g \\
-0.6 \\
-.5 \\
+.1\end{array}$ \\
\hline
\end{tabular}

TABLE 3. Results of determinations of zirconium and hafnium by the recommended procedure in "reactor grade" hafnium metals

\begin{tabular}{|c|c|c|c|}
\hline $\begin{array}{l}\text { Sample } \\
\text { number }\end{array}$ & $\begin{array}{l}\text { Sample } \\
\text { weight }\end{array}$ & Hafnium & Zirconium \\
\hline 2 & $\begin{array}{r}g \\
0.5 \\
.5 \\
.5 \\
.5 \\
.5 \\
.5 \\
.5\end{array}$ & $\begin{array}{c}\% \\
97.97 \\
97.98 \\
97.81 \\
97.85 \\
95.26 \\
95.29 \\
95.35\end{array}$ & $\begin{array}{c}\% \\
2.15 \\
2.06 \\
2.21 \\
2.16 \\
4.82 \\
4.79 \\
4.77\end{array}$ \\
\hline
\end{tabular}

\section{References}

[1] John L. Hague and Lawrence A. Machlan, J. Research NBS 65A (Phys. and Chem.) No. 1, 75 (1961).

[2] John L. Hague and Lawrence A. Machlan, J. Research NBS 62, 53 (1959) RP2929.

[3] John L. Hague, E. D. Brown, and H. A. Bright, J. Research NBS $\mathbf{5 3}, 262$ (1952) RP2542.

[4] John L. Hague, E. E. Maczkowske, and H. A. Bright, J, Research NBS 53, 353 (1954) RP2552.

[5] John L. Hague and Lawrence A. Machlan, J. Research NBS 62, 13 (1959) RP2923.

[6] R. B. Hahn, Anal. Chem. 23, 1259 (1951).

[7] G. Hevesy, Chem. Revs. 2, 12 (1925).

[8] K. A. Kraus and G. E. Moore, J. Am. Chem. Soc. 75 , $1460(1953)$

[9] G. E. Moore and K. A Kraus, J. Am. Chem. Soc. 74, 843 (1952).

(Paper 66A6-187) 


\section{Publications of the National Bureau of Standards ${ }^{\star}$}

\section{Selected Abstracts}

\begin{abstract}
Structure shielding against fallout radiation from nuclear weapons, L. V. Spencer, NBS Moro. 42 (June 1, 1962) 75 cents.

The theory of structure shielding from fallout gamma radiation is developed to the point of applications to elementary structure types. Examples discussed in the text include the density interface, shielded foxhole or basement, light superstructure, vertical wall, blockhouse, vents, compartmentalization effects, and mazes. A large number of engineering charts and graphs are presented for engineering calculations, including many obtained from angular distributions of the exposure dose. Results are given for a fission spectrum, and for $\mathrm{Co}^{60}$ and $\mathrm{Cs}^{137}$ sources. This information has been obtained almost completely by machine calculations utilizing basic cross section data. A number of sources of experimental data are mentioned, but detailed comparisons with experiment are not included.
\end{abstract}

Basic magnetic quantities and the measurement of the magnetic properties of materials, R. L. Sanford and I. L. Cooter, NBS Mono. 47 (May 21, 1962) 30 cents.

This paper gives general information regarding the two basic quantities, magnetic induction, $B$, and magnetizing force, $H$ and also the magnetic constant $\Gamma_{m}$ (often designated by the symbols $\mu_{n}$ and $\mu_{3}$. Information is also given regarding the magnetic properties of various materials and methods and apparatus commonly used in the Magnetic Measurements Section for measuring these properties by means of reversed direct current or alternating currents of low frequency. Magnetic measurements peculiar to high frequencies are not discussed. In view of the gradual adoption of the rationalized mksa system of units, this system is included as well as the classical cgs electromagnetic system.

Determination of total X-ray beam energy with a calibrated ionization chamber, J. S. Pruitt and S. R. Domen, NBS Mono. 48 (June 5, 1962) 20 cents.

This report describes the use of an air-filled aluminum-alloy ionization chamber to determine the energy transported by a bremsstrablung beam with maximum photon energy in the range 6 to 170 Mev. The experimental calibrations of this chamber over this energy range are given, as well as the result. of calibration experiments made with a $250-\mathrm{kv}$ constantpotential X-ray tube and with $\mathrm{Cs}^{137}$ and $\mathrm{Co}^{60}$ gamma-rays. Information is presented about the change in calibration when the chamber is used with different experimental conditions, and when either its dimensions or its alloy composition are changed slightly. This report can be used to construct a replica chamber and to determine its absolute calibration between 6 and $170 \mathrm{Mev}$ under a variety of experimental conditions.

Annotated bibliography on soft X-ray spectroscopy, H Yakowitz and J. R. Cuthill, NBS Mono. 52 (June 29, 1962) $\$ 1.00$.

About 550 references are contained in this bibliography which includes, it is believed, a complete coverage of the soft X-ray literature since 1950 and through 1960 . Some references to earlier work are given but the general review references, listed separately, give an adequate coverage of the earlier work.

The emphasis is on the application of soft $\mathrm{X}$-ray spectroseopy to the study of valence band electronic states in metals and alloys and therefore the spectral region of 25 to 800 angstroms involving ruled glass grating spectrometers is of principal interest. However, a wealth of data have been gathered, primarily by the Russians, on valence electronic states by means of high energy transitions where crystal spectrometers are satisfactory. These references and any X-ray work leading to the distribution of valence electronic states are included regardless of the transitions employed.
In addition to soft $\mathrm{X}$-ray data, references on all pertinent aspects of the apparatus and experimental problems are included. Also listed separately are references of value in corroborating soft X-ray data with other results, such as energy band calculations.

Subject, author, X-ray band, material, and other indices are included.

Weights and measures administration, NBS Handb. 82 (June 22, 1962) \$1.75. (Supersedes H26)

This Handbook presents a comprehensive picture of what an effective weights and measures program should embrace. The principles set forth are specifically recommended by the National Conference on Weights and Measures to all weights and measures officials and to the legislative bodies of States, counties, and cities. The Handbook should be helpful to agencies and individuals interested in setting up weights and measures supervision in a State or sub-division thereof, or concerned with strengthening such supervision where it now exists. It should also be useful as a training manual for new weights and measures officials and as a manual for review training for experienced officials, in the area of fundamental principles and general procedures.

OMNIFORM I: A general purpose machine program for the calculation of tables of functions given explicitly in terms of one variable, J. Hilsenrath and G. M. Galler, NBS Tech. Note 125 (PB161626) (1962) \$1.00.

A general purpose computer program, designed for use by non-programmers requiring computation of tables of functions written explicitly in terms of one variable, is described. The program features include: 22 types of elementary and special functions; provision for taking of functions of functions, table read-in, flexible print-out; and standardized input to a variety of problems. The use of the program is illustrated with a number of sample problems.

The thermodynamic properties of nitrogen from 64 to $300{ }^{\circ} \mathrm{K}$ between 0.1 and 200 atmospheres, T. R. Strobridge, NBS Tech. Note 129 (PB161630) (1962) \$2.25.

The internal energy, enthalpy, entropy, and specific volume of molecular nitrogen are derived and tabulated as functions of temperature and pressure. In addition to a mathematical model for the pressure-volume-temperature surface, accurate functions are given for the representation of the vapor pressure, density of saturated liquid, specific heat of saturated liquid, and the specific heat at zero pressure.

Tabular values in British units over the same pressure and temperature range are available as Supplement A of this Technical Note.

Detailed techniques for preparing and using hard gallium alloys, G. G. Harman, NBS Tech. Note 140 (PB16165i (1962) 75 cents.

This report presents an expansion and clarification of techniques for preparing and using dental-amalgam-type gallium alloys for industrial and scientific uses that were previously published in the Review of Scientific Instruments. In addi. tion, new material, such as hardness of the alloys and discussions of the bonding mechanism are presented. A different class of bonding alloys based on the same principals but not incorporating gallium are described, along with application details.

Dielectric constant of liquid parahydrogen, R. J. Corruceini, NBS Tech. Note 144 (PB161645) (1962) 50 cents.

It is shown that the available data on the dielectric constant of hydrogen conform to the Clausius-Mossotti equation within the probable experimental errors. The published data cover temperatures from the triple point $\left(\sim 14{ }^{\circ} \mathrm{K}\right)$ to well above room temperature and a thousandfold range of densities. 
Using an average value of the specific polarization, tables of the dielectric constant of the liquid have been computed for temperatures from the triple point $\left(13.803{ }^{\circ} \mathrm{K}\right)$ to $32{ }^{\circ} \mathrm{K}$ $\left(58^{\circ} \mathrm{R}\right)$ and pressures from saturation to 340 atmospheres.

A wire exploder for generating cylindrical shock waves in a controlled atmosphere, D. L. Jones and K. B. Earnshaw, NBS Tech Note 148 (PB161649) (1962) 50 cents.

A design for a rugged exploding wire device is given. This device permits the study of strong cylindrical shock waves in controlled atmospheres using optical and microwave techniques. Adequate detail and pictures are given to allow construction of the device.

Utilization of tritium and carbon-14 in studies of isotope effects, H. S. Isbell, H. L. Frush, and L. T. Sniegoski, Book, Tritium in the Physical and Biological Sciences II, 94-101 (International Atomic Energy Agency, Vienna, Austria, 1962). The utility of tritium in organic research has been augmented by the development of a simple method for determining $\mathrm{C}^{14}$ and tritium in the same sample. The non-volatile, radioactive material, in a film that is "infinitely thick" to tritium radiation, is counted in a windowless, gas-flow proportional counter; the film is then re-counted when covered with an absorber that stops all radiation from tritium, but allows a fraction of that from $\mathrm{C}^{14}$ to pass. The absorber used was $1 / 4$-mil, doublealuminized "Mylar" film.

By introduction of one isotope at a point removed from the reaction center, an isotope effect for the other can be determined from changes in the tritium- $\mathrm{C}^{14}$ ratio in the reactan and/or products as the reaction proceeds. Carriers of reactant, products or derivatives can be added at any point to facilitate isolation, because the analytical method depends primarily on the tritium- $\mathrm{C}^{14}$ ratio.

The isotope-effects in the bacterial oxidation of six C-14-or tritium-labeled D-mannitols and three tritium-labeled D-glucitols have been studied. Primary isotope effects (large for tritium, small for carbon-14) were found when the radioisotope was at the position of oxidation. A secondary isotope-effect was found for tritium at C3 of D-mannitol. A hypothesis is advanced to explain the difference in the oxidation behavior of the D-mannitols labeled with tritium at $\mathrm{C} 1$ and at $\mathrm{C} 3$.

Entropies, heats of sublimation and dissociation energies of the cesium halides, M. D. Scheer and J. Fine, J. Chem. Phys. 36: No. 6, 1647-1753 (Mar. 15, 1962).

The vapor pressures of the crystalline cesium halides have been measured in the $700-900^{\circ} \mathrm{K}$ temperature range. The salt vapor effusing from a Knudsen effusion cell was accurately collimated into a molecular beam wich a well defined cross sectional area. Beam intensities were determined from the positive ion currents produced by dissociation of the halide and ionization to $\mathrm{Cs}^{+}$on a tungsten surface at $1700^{\circ} \mathrm{K}$. From the experimental vapor pressures and heats of sublimation, the crvstal entropies, dissociation energies, and heats of sublimation at $298^{\circ} \mathrm{K}$ were computed using available spectroscopic and thermal data.

Deactivation of $\mathbf{H g}\left(6^{3} \mathbf{P}_{1}\right)$ by $\mathbf{C O}$ and $\mathbf{N}_{2} \mathrm{M}$. D. Scheer and J. Fine, J. Chem. Phys. 36: No. 5, 1264-1267 (Mar. 1962)

Atoms of $\mathrm{Hg}\left(6^{3} \mathrm{P}_{0}\right)$ produced by collisions between $\mathrm{Hg}\left(6^{3} \mathrm{P}_{1}\right)$ and either $\mathrm{N}_{2}$ or $\mathrm{CO}$ were detected by measuring the electrons ejected from a silver surface. From the pressure dependence of this effect, it was shown that the quenching of $\mathrm{Hg}\left(6^{3} \mathrm{P}_{1}\right)$ to $\mathrm{Hg}\left(6^{3} \mathrm{P}_{0}\right)$ by collision with $\mathrm{CO}$ occurs at about the same rate as with $\mathrm{N}_{2}$. Since $\mathrm{CO}$ is twenty times more efficient than $\mathrm{N}_{2}$ in the quenching of $2537 \AA$ fluorescence, the process $[\mathrm{Hg}$ $\left.\left(6^{3} \mathrm{P}_{1}\right)+\mathrm{CO} \rightarrow \mathrm{Hg}\left(6^{1} \mathrm{~S}_{0}\right)+\mathrm{CO} *\right]$ must be much faster than the corresponding reaction with $\mathrm{N}_{2}$. A possible explanation of this effect is the intermediate formation of $\mathrm{HgCO}^{*}$ which dissociates to $\mathrm{Hg}\left(6^{1} \mathrm{~S}_{0}\right)$ and vibrationally excited $\mathrm{CO}(\mathrm{v}=20)$. This could account for the fact that $\mathrm{H}_{2} \mathrm{CO}$ and $(\mathrm{HCO})_{2}$ are formed in the $\mathrm{Hg}$ photosensitized reaction of $\mathrm{N}_{2}$ and $\mathrm{CO}$ and not in the electric discharge experiments of $\mathrm{H}$ atoms reacting with ground state $\mathrm{CO}$.

The heat capacity of diamond at high temperatures, A. C. Victor, J. Chem. Phys. 36, No. 7, 1903-1911 (A pr. 1962).

The enthalpy of gem diamonds has been measured from 273 to $1073^{\circ} \mathrm{K}$ using a "drop" method and a Bunsen ice calorimeter. The derived heat-capacity values, which are believed to be accurate to \pm 0.5 percent, are used to calculate the thermal functions of diamond above $298.15^{\circ} \mathrm{K}$. Values of $\mathrm{C}_{\mathrm{v}}^{0}$ (harmonic) derived from the present investigation and recent measurements of the thermal expansion and the elastic constants of diamond are compared with theoretical treatments. Reasonably good agreement in the temperature range of this study can be obtained with a single Debye function $\left(\Theta_{D}=1860\right)$ obtained from the measured elastic constants. Extrapolation of the data gives $\Theta_{\infty}=1880 \pm 10$.

Millimeter wave techniques, W. Culshaw, Book, Advances in Electronics and Electron Physics XV, 197-263 (Academic Press, Inc., New York, N.Y., 1961).

The importance of millimeter waves both in research and in technology is outlined, and the difficulties experienced in the exploitation of these short wavelengths are made evident. Considerable attention is given to transmission and measurement problems, since conventional waveguide methods have serious limitations at short $\mathrm{mm}$ wave lengths. Optical and quasi-optical methods are discussed, and applications of $\mathrm{mm}$ wave interferometers and a $\mathrm{mm}$ wave spectrometer are considered, and diffraction effects treated in detail. The great potential use of the $\mathrm{mm}$ wave Fabry-Perot interferometer in precision measurements, and in maser research is made evident. Total reflection phenomena at $\mathrm{mm}$ wavelengths are presented and applications such as attenuation standards, phase changers, and polarizers are discussed. A re-entrant biconical spherical resonator is considered for operation at $\mathrm{mm}$ and sub-mm wavelengths, at high orders of interference. Expressions for the $\mathrm{Q}$ and shunt impedance are given, and results indicate that it could have direct application to the $\mathrm{mm}$ wave generation problem, and to solid state research at these wavelengths. Finally some practical aspects of $\mathrm{mm}$ wave detection and possible levels of sensitivity are given, together with some concluding remarks on millimeter wave research.

Transition probabilities for permitted and forbidden lines of Si X, Fe XIv and Fe x, R. H. Garstang, Extrait des Ann. d'Astrophys. 25, No. 2, 109-11\% (1962).

Transition probabilities have been calculated for forbidden transitions within the $2 s^{2} 2 p$ and $2 s 2 p^{2}$ configurations and for permitted transitions in the array $2 s^{2} 2 p-2 s 2 p^{2}$ of Si x. The energy levels of the $3 s 3 p^{2}$ and $3 s^{2} 3 d$ configurations in $\mathrm{Fe}$ XIV have been predicted by extrapolation along the isoelectronic sequence. Transition probabilities have been calculated for forbidden transitions within the $\left(3 s 3 p^{2}+3 s^{2} 3 d\right)$ configurations and for permitted transitions in the arrays $3 s^{2} 3 p-3 s 3 p^{2}$ and $3 s^{2} 3 p-3 s^{2} 3 d$ of Fe xiv. Some preliminary results are given for the $3 s^{2} 3 p^{5}-3 s 3 p^{6}$ and $3 s^{2} 3 p^{5}-3 s^{2} 3 p^{4} 3 d$ arrays in $\mathrm{Fe} x$. The effect of departures from LS-coupling due to spin-orbit interaction and configuration interaction is discussed.

The infiuence of temperature and pressure on the rheological properties of polymers. R. S. Marvin, J. Japan Soc. Testing Materials, Rheology Issue 11, 303-307 (May 1962).

The influence of temperature and pressure on viscosity and their corresponding influence on time dependent rheological properties is reviewed in terms of the free volume theory. Measurements obtained at the National Bureau of Standards on the effect of pressure on the dynamic bulk modulus of natural rubber and poly (vinyl acetate) are used to illustrate the usefulness of the free volume concept and to give some clues as to its validity. The results for natural rubber seem to agree very well with the predictions of the free volume theory; those for poly (vinyl acetate) show an unexplained discrepancy which indicates the need for further studies of other polymeric systems.

Plural scattering of $20-\mathbf{k e v}$ electrons in aluminum, L. Marton, J. A. Simpson, H. A. Fowler, and N. Swanson, Phys. Rev. 126, No. 1, 182-192 (Apr. 1, 1962).

The angular and energy-distrubution of $20 \mathrm{kev}$ electrons, scattered at very small angles $\left(\angle 10^{-2}\right.$, radians) by transmission through aluminum foils are compared with the theory of plural inelastic scattering, under the following assumptions: (a) The probability of elastic scattering at very small angles is negligibly small in comparison with the probability of 
inelastic scattering. (b) Inelastic scattering occurs predominantly through sharply-defined "characteristic" energy losses, whose number follows a Poisson statistical discribution. (c) The angular distribution in each loss follows a simple law: $\Phi(\theta) \propto 1 /\left(\theta_{\mathrm{E}}{ }^{2}+\theta^{2}\right)$, where $\theta_{\mathrm{E}}=\Delta \mathrm{E} / 2 \mathrm{E}$. (d) The cumulative angular distribution from plural inelastic seattering is obtained by repeated "folding" of $\Phi(\theta)$ with the angular spread of the incident beam. The angular distribution of zero-loss electrons is found to be substantially independent of the foil thickness; the normalized angular distributions of the 1- and 2-loss peaks are accurately fitted by the "folding" calculation; Poisson statisties give a good approximation to the observed numbers of energy losses. The value of $\lambda$ for five observations on foils of thicknesses $650-2580 \mathrm{~A}$ is approximately 810 A, independent of thickness; systematic errors in the method of observation may render this value up to $20 \%$ higher than the mean free path corresponding to the total cross-section.

The international standard of light, R. P. Teele, J. Opt. Soc. A m. 52, No. \%, 826 (July 1962).

In 1931 Wensel et al. reported the practical realization of the suggestion, made in 1908 by Waidner and Burgess, that a blackbody radiator at the freezing point of pure platinum be used as a standard of light. Subsequently such a standard was adopted internationally, effective January 1, 1948. From 1957 to the present time investigations of factors affecting the reproducibility of the standard have been conducted at the National Bureau of Standards. The previous work was extended to include crucibles and sight tubes of different dimensions and immersed to various depths, and the use of various freezing patterns. The application of corrections for the necessary viewing aperture, for the temperature drop in the walls of the sight tube, and for the unimmersed portion of the sight tube, enable us to evaluate the ideal blackbody radiator from observed values obtained with practical radiators. Appropriate modification of the freezing pattern yields improved precision. It is found that the standard is reproducible to well within 0.1 percent.

It is planned to present a complete discussion and results in the Journal of Research of the NBS.

Effect of gamma radiation on chemical structure of plastics, V. J. Krasnansky, M. S. Parker, and B. G. Achhammer, SPE Trans. 1, 133-138 (July 1961).

Twelve plastics representing various chemical structures were studied as part of a program to determine the utility of plastics as packaging materials in the high energy radiation preservation of food. The plastics were exposed to selected dosages of Cobalt-60 gamma radiation, in vacuum and in air Gas evolution and changes in infrared spectra as a result of irradiation were used to hypothesize the relative stability of these plastics to irradiation. On the basis of these criteria it was found that plastics containing conjugated ring systems, ionic linkages, and chlorine in side groups were the most stable.

Thermal degradation of polymers at temperatures up to $1200{ }^{\circ}$ C, S. L. Madorsky, Soc. Chem. Ind. Mono. No. 13, 60 74 (1961).

A study was made of the thermal degradation of polymers in a vacuum and in some cases in helium at atmospheric pressure. using 10 to $50 \mathrm{mg}$ samples. Polymethylene, a noncrosslinked polymer, when heated for about half an hour in a vacuum or in helium at $500{ }^{\circ} \mathrm{C}$, vaporizes without leaving a residue. The volatile products consist of a series of saturated and unsaturated hydrocarbons of various molecular weights. At $800{ }^{\circ} \mathrm{C}$ and higher, pyrolysis gives similar results; however, the products are more fragmented, and the higher the temperature and pressure the greater is this fragmentation. Polytrivinylbenzene, which is a highly crosslinked polymer, and poly(vinylidene fluoride), which is one that develops crosslinkings during pyrolysis, both yield on heating in a vacuum at any pyrolysis temperature various volatile fragments and a more or less carbonized residue. Here too, as in the case of polymethylene, a higher temperature produces greater fragmentation of the volatile products. The more volatile products were analyzed by mass spectrometry, and the less volatile products were tested for their average molecular weight by a microcryoscopic method. Elemental analysis of residues were made by a microchemical method.
Growth rates of zinc crystals from the vapor phase, R. L Parker and L. M. Kushner, J. Chem. Phys. 35, No. 4, 1345 (Oct. 1961).

The rate of growth of zinc crystals from the vapor phase has been studied as a function of the vapor supersaturation $\sigma$ at a temperature of $390{ }^{\circ} \mathrm{C}$. The $\sigma$-values ranged between 0.009 and 0.09 . The rate $\mathrm{R}$ was found to vary approximately linearly with $\sigma$, permitting estimates to be made of the two parameters $\sigma_{1}$ and $\beta \mathrm{C}_{0}$, appearing in the Burton, Cabrera and Frank theory of crystal growth. The results indicate that surface nucleation was not operative in either the nucleation or the growth of these crystals.

Heats of formation of inorganic fluorine compounds - A survey, G. T. Armstrong and L. A. Krieger, Progress on Intern. Research on Thermodynamics and Transport Properties, p. 8-7\% (ASME \& Academic Press, Inc., New York, N.Y., 1962)

This paper demonstrates the present state of measurements leading to heats of formation for the inorganic fluorine compounds. An attempt is made to show the relative magnitudes of the areas in which measurements are lacking, as compared to the areas in which data exist. No attempt is made to indicate the best values to be assigned where conflicting data exist. As a group, the binary compounds have been the most thoroughly studied. The coverage of thermodynamic information decreases rapidly as the complexity of the compounds increases. Organic compounds aside from the substituted methanes are not discussed.

A bibliography containing 513 entries dealing with thermochemical work on fluorine compounds published in the last decade is included. A lengthy table is given in which are listed fluorine and compounds, in which fluorine is combined with one, two, three and more other elements, and aqueous species of these same classes of substances. For each substance, references are given to experimental and theoretical work and other reviews giving the heat of formation or other data directly applicable to the calculation of the heat of formation.

Vibration-rotation spectra of BrCN, A. G. Maki and C. T. Gott, J. Chem. Phys. 35, No. 9, 2282-2285 (1962).

The vibration-rotation structure of the infrared absorption bands due to $\nu_{2}^{1}+\nu_{3}, 2 \nu_{2}^{0}+\nu_{3}$, and $\nu_{1}+\nu_{3}$ have been observed and measured for $\mathrm{Br}^{79} \mathrm{CN}$ and $\mathrm{Br}^{81} \mathrm{CN}$. The average value of $\alpha^{3}$ for these two isotopes was found to be $+0.000677 \mathrm{~cm}^{-1}$. The Fermi resonance constant for the resonance diad was calculated to be $W_{12}=35.41 \mathrm{~cm}^{-1}$ for $\mathrm{Br}^{79} \mathrm{CN}$ and $\mathrm{W}_{12}=35.48$ $\mathrm{cm}^{-1}$ for $\mathrm{Br}^{81} \mathrm{CN}$. The positions of the $Q$ branches of a number of other bands were also measured.

Electron spin resonance studies of $\gamma$-irradiated small molecules at $4^{\circ} \mathrm{K}$ and $77^{\circ} \mathrm{K}, \mathrm{R}$. E. Florin, D. W. Brown, and I. A. Wall, Proc. 5th Intern. Symp. on Free Radicals, Paper No. 18, 1-17 (Almquist and Wiksell, Stockholm, Sweden, July $6-7,1961)$.

Electron spin resonance spectra were observed for the species $\mathrm{H}, \mathrm{D}, \mathrm{N}, \mathrm{CH}_{3}, \mathrm{CF}_{3}$, and $\mathrm{SiF}_{3}$, produced by gamma irradiation of $\mathrm{H}_{2}, \mathrm{D}_{2}, \mathrm{~N}_{2}, \mathrm{CH}_{4}, \mathrm{CF}_{4}$, and $\mathrm{SiF}_{4}$, respectively, at $4{ }^{\circ} \mathrm{K}$, and of $\mathrm{CH}_{4}, \mathrm{CF}_{4}$, and $\mathrm{SiF}_{4}$ mixed with Xe at $77^{\circ} \mathrm{K}$. The yields of $\mathrm{CH}_{3}$ and $\mathrm{CF}_{3}$ radicals per $100 \mathrm{ev}$ absorbed (G-values) were much lower at $77^{\circ} \mathrm{K}$. No radicals were found at $77^{\circ} \mathrm{K}$ in pure $\mathrm{CH}_{4}$ and $\mathrm{CF}_{4}$. The $\mathrm{CH}_{3}$ and $\mathrm{CF}_{3}$ spectra are closely similar to each other in Xe mixtures at $77^{\circ} \mathrm{K}$. The spectrum from $\mathrm{CF}_{4}$ irradiated at $4{ }^{\circ} \mathrm{K}$ is totally different from the spectrum at $77^{\circ} \mathrm{K} . \mathrm{SiF}_{3}$ has a characteristic complicated spectrum at all temperatures. Decay phenomena are mentioned briefly.

Direct measurement of line intensities and widths in the first overtone band of $\mathrm{CO}, \mathrm{H}$. J. Kostkowski and A. M. Bass, J. Quant. Spectry. Radiative Transfer 1, 17\%-184 (1961).

The absolute intensities and widths of self-broadened lines in the first overtone band of carbon monoxide were measured directly with a small grating monochromator to an estimated accuracy of 5 percent. The intensities were obtained at CO pressures below one atmosphere and the widths at pressures from $2^{1 / 2}$ to 20 atmospheres. Slit function corrections were 
made using the results of a paper previously published by the authors. The intensities were found to fit the results of the rotation-vibration interaction calculation of Herman and Waiiis. Spectral transmission calculations assuming a Lorentz shape for all the lines fit the observed data up to 20 atmospheres pressure

Dislocaiions and stacking faults in aluminum nitrides, $\mathrm{P}$ Delavignette, H. B. Kirkpatrick, and S. Amelinckx, J. Appl. Phys. 32, No. 6, 1098-1100 (June 1961).

The recently developed methods for the direct observation of dislocations by means of transmission electron microscopy have now been applied to aluminium nitride single crystal plates, obtained by growth from the vapour phase. The crystal plates, which were developed parallel to the c-face, were thin enough to transmit electrons as grown.

Absolute isotopic abundance ratio and the atomic weight of chlorine, W. R. Shields, E. L. Garner, and V. H. Dibeler, J. Am. Chem. Soc. 84, 1510-1522 (1962).

An absolute value is obtained for the isotopic abundance ratio of natural chlorine by surface emission mass spectrometry and by the use of calibration samples of known isotopic composition prepared from nearly pure separated chlorine isotopes. The data result in the absolute value for the $\mathrm{C} 1^{35} / \mathrm{C}^{37}$ ratio $=3.1272+0.0062$. The atomic weight on the unified scale $\left(\mathrm{C}^{12}=12\right)$ is $35.45273_{-0.00089}^{+0.00073}$ The indicated uncertainties are over-all limits of error based on $95 \%$ confidence limits for the mean and on allowances for effects of known sources of possible systematic error.

Temperature dependence of electron emssion in the field emission region, R. Klein and L. B. Leder, Phys. Rev. 124, 1046-1049 (Nov. 1961).

The variation in field emission current as a function of the temperature of the emitter has been measured for tungsten over the range from $4.2^{\circ} \mathrm{K}$ to $400{ }^{\circ} \mathrm{K}$. The expected form of the temperature dependence of the emission current confirms the relationship previously postulated on theoretical grounds. This is $\mathrm{j}(\mathrm{T})=\mathrm{j}(\mathrm{o}) \frac{\mathrm{KT}}{\sin \mathrm{KT}}$ where $\mathrm{K}$ is a constant depending on the work function and the field at the surface of the emitter. A current-increment method, in which the increase of current is plotted against the square of the temperature increase at constant field, gives a straight line whose slope permits surface field calculations more precise than heretofore possible by electron microscope measurement of tip radius.

Ultra-high vacuum ultraviolet monochromator, L. Marton, J. A. Simpson, J. A. Suddeth, and L. B. Leder, 1961 Trans. 8th Natl. Vacuum Symp., 2d Intern. Congress, Ed. L. F Prauss, p. 633-639 (Pergamon Press, Inc., New York, N.Y. 1962)

A 1-meter, normal incidence vacuum ultraviolet monochromator having a sample chamber pressure of approximately $1 \times 10^{-9} \mathrm{~mm} \mathrm{Hg}$ is described. The entrance and exit slits are on the Rowland circle while the center floats. Wavelength is scanned by moving the grating along the circle. All moving parts are external to the vacuum chamber. The high vacuum conditions are obtained by several stages of differential pumping from the lamp housing to the sample chamber. The entire monochromator is of stainless steel with welded joints. Interesting vacuum features are the flange design, liquid nitrogen traps and rotary sea.

Field emission from niobium in the normal and superconducting states, R. Klein and L. B. Leder, Phys. Rev. 124, No. 4, 1050-1052 (Nov. 1961).

The change of field emission current from a superconductor as a result of a transition to the normal state under constan field and temperature conditions was calculated. The derivation is based on the Bardeen-Cooper-Schrieffer formulation of the density of states and band gap model for a superconductor. The experimental method for determining the current charge consisted in measuring the current increment between a niobium field emitter in the superconducting state at $4.2{ }^{\circ} \mathrm{K}$ and in the normal state at a temperature $\mathrm{T}$ above the transition. After correcting for the current increase occurring as a result of the temperature increase alone, the residual would be that associated with the superconductingnormal transition. This was less than the detectability of the measurements, although the calculations indicated an expected increase in current easily measurable if the superconducting-normal transition had occurred at the emitter surface. It is speculated that under high field conditions, the superconducting state is quenched at the surface.

On the self-diffusion of ions in a polyelectrolyte solution, $\mathrm{S}$ Lifson and J. L. Jackson, J. Chem. Phys. 36, No. 9, 2410-2414 (May 1962).

The self-diffusion of ions in a polyelectrolyte solution is investigated both with respect to the average time an ion is associated with a particular polyelectrolyte molecule and with respect to the effect of the electrostatic field of the macroions on the macroscopic self-diffusion constant. The results on the macroscopic self-diffusion constant are shown to be generally compatible with experiments on self-diffusion of councerions in polyelectrolyte solutions. On the other hand, the study of the time of association of a counterion with a particular macroion vields results which cannot be reconciled with the common interpretation of transference experiments on the same solutions.

Time resolved electron optical image of a pulsed atomic beam in flight, L. Marton, S. R. Mielczarek, and D. C. Schubert, J. Appl. Phys. 33, No. 4, 1613-1614 (Apr. 1962).

The electron optical schlieren method for study of gas behavior at very low pressures has been applied in stroboscopic fashion to produce photographs of chopped atomic beam pulses in flight. A photograph is shown of a cadmium atomic beam pulse moving at approximately 300 meters/sec. with maximum atomic density corresponding to about $2 \cdot 10^{-6} \mathrm{~mm}$ $\mathrm{Hg}$ equilibrium pressure. The potential usefulness of this technique for study of accommodation coefficients on aerodynamic surfaces is described briefly.

An electron resonance magnetometer for alternating magnetic fields, O. E. Spokas and M. Danos, Rev. Sci. Instr. 33, No. 6, 613-617 (June 1962).

Alternating magnetic fields in the range of 2,800 gauss to 4,300 gauss are measured in terms of the frequency of the free electron spin resonance in 1:1-Diphenyl-2-picryl hydrazyl. The probe is constructed entirely of dielectric materials. An accuracy of 0.1 percent in the field determination was obtained.

Optical studies at high pressures using diamond anvils, C. E. Weir, A. Van Valkenburg, and E. Lippincott, Book, Modern Very High Pressures Techniques, Ed., R. H. Wentorf, Jr., p. 51-69 (Butterworth \& Co., London, England, 1962).

A pressure cell capable of maintaining pressures up to 160,000 atmospheres has been constructed using a pair of type II diamonds for studies in the infrared, visible and ultraviolet spectrum. Temperature variations from $175^{\circ}$ to $-30{ }^{\circ} \mathrm{C}$ can be obtained with the cell. Major effects observed in the infrared spectrum of substances under pressure include shifts in absorption bands to both higher and lower frequencies, occurrence of new band as well as elimination of existing bands, the splitting of bands and changes in apparent band intensities. Examples of these effects using the infrared spectra of sodium nitrite, calcite, succinic acid, ice and ferrocene are given.

The molecular structure of chlor oform, M. Jen and D. R. Lide, Jr., J. Chem. Phys. 36, No. 9, 2525 ( May 1962).

The structural parameters of the chloroform molecule have been previously calculated from microwave measurements on the $\mathrm{CHCl}_{3}{ }^{35}, \mathrm{CDCl}_{3}{ }^{35}, \mathrm{CHCl}_{3}{ }^{37}$, and $\mathrm{CHCl}_{2}{ }^{35} \mathrm{Cl}^{37}$ species. The rather short $\mathrm{CH}$ distance which was reported $(1.073 \mathrm{~A}$, as compared to $1.09-1.10 \mathrm{~A}$ in $\mathrm{CH}_{4}, \mathrm{CHF}_{3}$ and the methyl halides) has prompted a re-examination of the chloroform spectrum. We have now measured the $\mathrm{C}^{13} \mathrm{HCl}_{3}{ }^{35}$ species in natural abundance and have also carried out measurements on the other species under comparable conditions in order to obtain a selfconsistent set of data for a structure determination by the substitution $\left(\mathrm{r}_{\mathrm{s}}\right)$ method. 
Collision-induced microwave absorption in compressed gases. II. Molecular electric quadrupole moments, G. Birnbaum and A. A. Maryott, J. Chem. Phys. 36, 2032-2036 (Apr. 1962). $\mathrm{A}$ search for dielectric loss in the nondipolar gases, He, A, $\mathrm{CH}_{4}, \mathrm{SF}_{6}, \mathrm{H}_{2}, \mathrm{C}_{2} \mathrm{H}_{6}, \mathrm{~N}_{2}$, and $\mathrm{C}_{2} \mathrm{H}_{4}$ was made at a frequency near $24 \mathrm{kMc}$ and for densities not exceeding 100 amagat. For the first six gases, the loss factor was immeasurably small, less than $2 \times 10^{-7}$, at the maximum density. The loss observed in nitrogen and ethylene is attributed to transient dipoles induced by the molecular quadrupole fields during binary colisions. From the data on the quadrupolar gases, including previous results on $\mathrm{CO}_{2}$, values of the quadrupolar moments (or upper limits where no loss was observed) are derived which are in reasonable agreement with other estimates.

Formation constant of the 1:1 pyridine-iodine complex, A. G. Maki and E. K. Plyler, J. Phys. Chem. 66, 766-767 (1962)

The equilibrium constant for $\mathrm{PvI}_{2}$ in inert organic solvents has been measured using two different infrared bands, one at $601 \mathrm{~cm}^{-1}$ and the other at $184 \mathrm{~cm}^{-1}$. The solvents n-heptane, $\mathrm{CCl}_{4}$, and cyclohexane all gave approximately identical results. From intensity measurements of the infrared bands the best value for the constant was found to be $107 \pm 251 /$ mole at $26{ }^{\circ} \mathrm{C}$. Consideration is given to the possible errors due to other pyridine-iodine complexes such as $\mathrm{Py}_{2} \mathrm{I}_{8}$. Evidence concerning the structure of this 1:2 pyridine-iodine complex is also presented.

Analytical Chemistry of Polymers, Parts II and III, Ed., G. M. Kline (Vol. XI I of High Polymers Series, Interscience Publishers, New York, N.Y., 1962.)

These books have been planned and written by staff members of the National Bureau of Standards Polymers Division to survey measurement techniques for the determination of structure and composition of macromolecules and to summarize our present knowledge in this field. Modern instrumental methods of analysis are stressed; many of these techniques have been undergoing active development and perfection during the period in which these chapters have been written.

Each chapter in Part II presents the basic theory underlying the application of an instrumental method of analysis to the exploration of the structure of polymers. This is followed by descriptive information on available equipment and procedural details. Comprehensive data are presented on the characteristics of polymers as determined by the various analytical techniques. Finally, the authors review the application of this information to analytical problems and to investigations of polymerization processes, polymer structure, stability, and related research.

Identification of polymers by systematic procedures, color tests, and microscopic examination are covered comprehensively in the first three chapters of Part III. The two concluding chapters describe important developments in the application of radiochemical and end-group analysis to the unravelling of the complex composition of macromolecules. The subject matter of all chapters is fully tied to the published literature by extensive lists of references. These two volumes provide a broad review of developments in modern methods of polymer analysis, supplementing the information presented in Part I (published in 1959) on the control methods used in the analytical laboratories of materials manufacturers. The titles and authors of the chapters in Parts II and III are as follows:

Part II. Analysis of Molecular Structure and Chemical Groups. 619 pages.

I. Molecular weights and sizes, S. G. Weissberg, S. Rothman, and M. Wales, p. 1-77.

II. X-ray diffraction, A. S. Posner, p. 79-108.

III. Optical methods, A. F. Forziati, p. 109-157.

IV. Differential thermal analysis, H. E. Kissinger and S. B. Newman. p. 159-179.

V. Pyrolysis, L. A. Wall, p. 181-248.

VI. Mass spectrometry, L. A. Wall, p. 249-268.

VII. Ultraviolet spectrophotometry, M. Tryon and E. Horowitz, p. 269-289.
VIII. Infrared spectrophotometry, M. Tryon and E. Horowitz, p. 291-333.

IX. Fluorescence, A. F. Forziati, p. 335-357.

X. Chromatography, J. M. Cassel, p. 359-404.

XI. Polarography, G. M. Brauer, p. 405-485.

XII. Magnetic resonance spectroscopy, L. A. Wall and R. E. Florin, p. $487-559$.

Author index. Subject index, p. 561-619.

Part III. Identification Procedures and Chemical Analysis. 566 pages.

I. Systematic procedures, G. M. Brauer and E. Horowitz, p. $1-140$

II. Color tests, G. M. Brauer and S. B. Newman, p. $141-259$

III. Microscopy, S. B. Newman, p. 261-348.

IV. Radiochemical analysis, R. E. Florin and L. A. Wall, p. 349-395.

V. End-group analysis, M. Hellmann and L. A. Wall, p. 397-411.

General references. Pages 413-419.

Cumulative subject and author index. Pages 421-566.

\section{Other NBS Publications}

Journal of Research 66C (Eng. and Instr.) No. 4 (Oct.-Dec. 1962) 75 cents.

An ultra-high speed image dissecting camera for photographing strong shock waves. K. B. Earnshaw and C. M. Benedict.

Biprism method of determining the equivalent focal length of flat field lenses. W. R. Darling.

Effect of air drag on the motion of a filament struck transversely by a high-speed projectile. F. L. McCrackin.

A precision noise spectral density comparator. C. M. Allred.

Stresses in a plate uniformly compressed over portions of its two opposite edges. M. Chi and W. D. Kroll.

Studies of the stress-corrosions cracking of low-carbon steels. H. L. Logan.

A dual centrifuge for generating low-frequency sinusoidal accelerations. R. O. Smith, E. A. Willis, and J. S. Hilten.

Rotational micromanometers. K. Lofquist.

Study of gypsum plasters exposed to fire. J. V. Ryan.

Journal of Research 66D (Radio Prop.) No. 6 (Nov.-Dec. 1962) 70 cents.

$\mathrm{RF}$ impedance probe measurements of ionospheric electron densities. J. A. Kane, J. E. Jackson, and H. A. Whale.

Methods for applying numerical maps of ionospheric characteristics. W. B. Jones and R. M. Gallet.

Very-low-frequency radio propagation in the ionosphere. D) W Swift.

Prolonged space-wave fadeouts in tropospheric propagation. A. P. Barsis and M. E. Johnson.

Range-error compensation for a troposphere with exponentially varying refraetivity. J. J. Freeman.

On the geometrical optics of curved surfaces with periodic impedance properties. C. J. Marcinkowski and L. B. Felsen.

On the limitations of geometrical optics solutions for curved surfaces with variable impedance properties. C. J. Marcinkowski and L. B. Felsen.

Conversion of the amplitude-probability distribution function for atmospheric radio noise from one bandwidth to another. A. D. Spaulding, C. J. Roubique, and W. Q. Crichlow.

Some statistical properties of pulsed oblique HF ionospheric transmissions. M. Balser and W. B. Smith.

Induction in a small loop moving with a magnetostatic dipole toward a conducting half space. M. B. Kraichman.

Propagation of terrestrial radio waves of long wavelengththeory of zonal harmonics with improved summation techniques. J. R. Johler and L. A. Berry.

Terminal-zone corrections for a dipole driven by a two-wire line. K. Iizuka and R. W. P. King.

Pattern synthesis with a flush-mounted leaky-wave antenna on a conducting circular cylinder. A. Ishimaru and F. R. Beich.

Analvsis of electric energy usage in Air Force houses equipped with air-to-air heat pumps, P. R. Achenbach, J. C. Davis, and W. T. Smith, NBS Mono. 51 (July 13, 1962) 30 cents. 
Specifications, tolerances, and regulations for commercial weighing and measuring devices (corrected through 1961), NBS Handb. 44, 2d Ed. (1961) \$1.00.

Index to the reports of the National Conference on Weights and Measures. From the first to the forty-fifth, 1905 to 1960. NBS Misc. Publ. 243 (June 28, 1962) 30 cents (Supersedes M203).

Quarterly radio noise data-December, January, February 1961-62, W. Q. Crichlow, R. T. Disney, and M. A. Jenkins, NBS Tech. Note 18-13 (PB151377-13) (1962) \$1.75.

Characteristics of point-to-point tropospheric propagation and siting considerations, R. S. Kirby, P. L. Rice, and L. J. Maloney, NBS Tech. Note 95 (PB161596) (1961) $\$ 2.50$.

Analysis of ionospheric vertical soundings for electron density profile data. III. Procedures for obtaining monthly summary virtual height curves for $\mathrm{N}(\mathrm{H})$ analysis (composite virtual height curves), J. W. Wright, NBS Tech. Note 146 (PB-161647) (1962) 75 cents

\section{Publications in Other Journals}

Propagation of solar particles and the interplanetary magnetic field, C. S. Warwick, J. Geophys. Research 6\%, No. 4, 1333-1346 (Apr. 1962).

Availability of machine-usable natural language material, M. E. Stevens, Proc. 3d Inst. on Information, Storage and Retrieval (American Univ., Washington, D.C.) 1, 58-75 (Feb. 1961).

Physical measurements and experiment design, W. J. Youden, Le Plan d'Exper. Centre Natl. Recherche Sci. (Paris, France) 110, 1-13 (Aug.-Sept. 1961).

A calculus for factorial arrangements, B. Kurkjian and M. Zelen, Annals of Math. Statisties 33, 600-619 (June 1962).

Plastics, G. M. Kline, Encyclopedia Americana XXII, 221229 (1962 Ed.).

Modular forms whose coefficients possess multiplicative properties (II), M. Newman, Ann. of Math. 75, 242-250 (Mar. 1962).

A note on normal matrices, M. Marcus and N. Khan, Can. Math. Bull. 4, 23-27 (1961).

A statistical comparison of the wearing characteristics of two types of dollar notes, E. B. Randall, Jr., and J. Mandel, Materials Research and Standards (ASTM Bull.) 2, No. 1, 17-20 (Jan. 1962).

Study of the effect of large aperture on the performance of an Ebert spectrometer, L. R. Megill and L. Doppleman, J. Opt. Soc. Am. 52, No. 3, 258-261 (Mar. 1962).

Prediction of pressure drop in two-phase single-component fluid flow, M. R. Hatch and R. B. Jacobs, A.I.Ch.E. Journal 8, No. 1, 18-25 (Mar. 1962).

Potential heat: A method for measuring the heat release of materials in building fires, J. J. Loftus, D. Gross, and A. F. Robertson, Am. Soc. Testing Materials Proc. 61, 1336-1348 (June 1961).

Comparison of standard and microtests for international rubber hardness, R. D. Stiehler and F. L. Roth, Materials Research and Standards (ASTM Bull.) 2, No. 5, 388-391 (May 1962)

Comments on "Effects of ultrahigh pressures on glass", C. E. Weir and S. Spinner, J. Am. Ceramic Soc. 45, No. 4, 196 (Apr. 1962).

The "vicious cycle" in secondary batteries - a mathematical approach, W. G. Eicke, Jr., J. Electrochem. Soc. 109, No. 5, 364-368 (May 1962).

Communication between man ānd machine, S. N. Alexander and J. E. Karlin, Proc. IRE 50, No. 5, 1124-1128 (May 1962).

The radio refractive index of air, B. R. Bean, Proc. IRE 50, No. 3, 260-273 (Mar. 1962).

The reflection of logistics in electronic computer design, E. W. Cannon, Naval Research Logistics Quart. 7, 365$371(1960)$

Variability of spectral tristimulus values, I. Nimeroff, J Opt. Soc. Am. 52,1 No.16, 685-691 (June 1962).
The propagation of electromagnetic waves along the earth's surface, J. R. Wait, Book, Electromagnetic Waves, Ed. by R. E. Langer, p. 243 (The University of Wisconsin Press, Madison, Wisc., 1962)

Emission flame photometry, M. Margoshes, Anal. Chem. 34, No. 5, 221R-224R (Apr. 1962)

An auroral-zone electron precipitation event and its relationship to a magnetic bay, R. R. Brown and W. H. Campbell, J. Geophys. Research 6\%, No. 4, 1357-1366 (Apr. 1962).

Tungsten helical-spring microbalance, S. L. Madorsky, Vacuum Microbalance Techniques $2,47-57$ (Plenum Press, Inc., New York, N.Y., 1962).

Thermal explosives: adiabatic self-heating of explosive and propellants, D. Gross and A. B. Amster, Eighth Symp. (Intern.) on Combustion, p. 728-734 (The Williams and Wilkins Co., Baltimore, Md., 1962).

The evolution of concepts and languages of computing, R. D. Elbourn and W. H. Ware, Proc. IRE 50, No. 5, 1059-1066 (May 1962).

National Bureau of Standards list of IGY flares with normalized values of importance and area, C. S. Warwick, IGY Solar Activity Report Series No. 17 (Intern. Geophvs. Year, World Data Center A. Solar Activity, High Altitude Observatory, University of Colorado, Boulder, Colorado, May 1, 1962).

Extension of the Flory-Rehner theory of swelling to an anisotropic system, S. D. Bruck, J. Polymer Sci. 55, 29-31 (Dec. 1961).

Polymer degradation (by heat, oxidation and radiation), in unsolved problems in polymer science, L. A. Wall, ASD Tech. Report 62-283, p. 32-36 (Mar. 1962).

Time and its inverse, J. M. Richardson, Intern. Sci. and Tech. 1, No. 6, 54-61 (June 1962).

Effect of crystal growth on the comparative fixation of $\mathrm{Sr}^{89}$ and $\mathrm{Ca}^{45}$ by calcified tissues, R. C. Likins, A. S. Posner, B. Paretzkin, A. P. Frost, J. Biol. Chem. 236, 2804-2806 Oct. 1961).

Infrasonic pressure waves associated with magnetic storms, P. Chrzanowski, J. M. Young, G. Greene, and K. T. Lemmon, J. Phys. Soc. Japan 17, Suppl. A-II, 9-13 (1962).

Characterization of textile yarns for use under ballistic impact conditions, J. C. Smith, Proc. Symp. Personnes Armor, U.S. Naval Research Laboratory I, 1-21 (Oct. 4-5, 1961).

Introduction, H. S. Peiser, Book, Vacuum Microbalance Techniques, Ed., R. F. Walker, 2, 1-5 (Plenum Press, Inc., New York, N.Y., 1962).

Charge-storage techniques for pulse-height analysis, L. Costrell and R. E. Brueckman, Nuclear Electronics (Intern. Atomic Energy Agency) II, 29-39 (1962).

Glass Dewars for optical and other studies at low temperatures, L. J. Schoen and H. P. Broida, Rev. Sci. Instr. 33, No. 4, 470-473 (Apr. 1962).

The effect of geomagnetic activity on the $\mathrm{F}_{2}$ region over central Africa, R. G. Rastogi, J. Geophys. Research 67, No. 4, 1367-1374 (Apr. 1962).

Distillation analysis, R. T. Leslie and E. C. Kuehner, Anal. Chem. Suppl. 34, No. 5, 50R-56R (Apr. 1962).

Plastic standards in Government, F. W. Reinhart, Proc. Am. Standards Assoc. 12th Natl. Conf. Standards, p. 44-46 (Houston, Texas, Oct. 1961).

Anisotropies in angular distributions of molecular dissociation products, G. H. Dunn, Phys. Rev. 8, 62-64 (Jan. 15, 1962).

Plastics, G. M. Kline, The Americana Annual, p. 603 (Americana Corp., Chicago, Ill., 1961)

Displacement and strain-energy distribution in a longitudinally vibrating cylindrical rod with a viscoelastic coating, P. Hertelendy, J. Appl. Mech. 29, Series E, 47-52 (Mar. 1962).

Distribution of total service time for a fixed observation interval, W. S. Connor and N. C. Severo, J. Am. Stat. Assoc. 5\%, 376-386 (June 1962).

Abstract shape recognition by machine, M. E. Stevens, Computers - Key to Total Systems Control, Proc. Eastern Joint Computer Conf. 20, No. 1, 332-351 (Dec. 1961). 
Catalytic effects of thermocouple materials, L. O. Olsen, SAE J. Paper No. 524G, 70, No. 5, 94 (May 1962).

Determination of molecular weights and molecular weight distribution, D. McIntyre, ASD Tech. Rept. 62-283, p. 71-74 (Mar. 1962).

Characteristics of some air-turbine handpieces, D. F. Taylor, R. R. Perkins, and J. W. Kumpula, J. Am. Dental Assoc. 64, No. 6, 794-805 (June 1962).

Tensile shear strength of adhesive bonded metals as a function of the rate of loading, D. A. George, H. R. Butzlaff, and J. Mandel, Symp. on Adhesion and Adhesives, Am. Soc. Testing Materials Spec. Tech. Publ. No. 271, 47-53 (1961).

Enviromental chemistry, F. W. Reinhart, Prevention of Deterioration Center Newsletter (Natl. Acad. Sci.-Natl. Research Council) V, No. 1, 1-2, 4 (Oct. 1961).

A study of solar activity associated with polar-cap absorption, C. S. Warwick and M. W. Haurwitz, J. Geophys. Research 67, No. 4, 1317-1332 (Apr. 1962).

Stability of plastic impression trays, J. B. Woelfel and G. C. Paffenbarger, J. Am. Dental Assoc. 63, No. 5, 705-706 (Nov. 1961).

Vacuum system for use with a microbalance, G. F. Rouse, Book, Vacuum Microbalance Techniques, Ed., R. F. Walker, 2, 5969 (Plenum Press, Inc., New York, N.Y., 1962).

Departure from the steady state in two-intermediate enzyme reactions, H. Shin, Trans. Faraday Soc. 58, No. 475, 1439-1450 (July 1962).

Calibration of vibration pickups at large amplitudes, E. Jones, S. Edelman, and K. S. Sizemore, J. Acoust, Soc. Am. (Errata) 34, No. 3, 355 (Mar. 1962).

Pair production as an analyzer of circular polarization of gamma rays from neutral particle decays, $H$. Olsen and L. C. Maximon, Il Nuovo Cimento 24, No. 1, 186-189 (Apr. 1962).

Emission flame photometry, M. Margoshes, Anal. Chem. Suppl. 34, No. 5, 221R-224R (Apr. 1962).

Design requirements for mechanized systems in protective shelters, R. R. Achenbach, Heating, Piping and Air Conditioning 34, No. 2, 73-79 (Feb. 1962).

Creep of pure-gum rubber vulcanizates from indentationtime measurements, L. A. Wood and F. I. Roth, Rubber Tech. Conf. (London, England, 1962).

The ideal Lovibond color system, D. B. Judd, G. J. Chamberlin, and G. W. Haupt, J. Opt. Soc. Am. 52, No. 7, 813-819 (July 1962).

Single-trace sweep adapter for transistor-curve tracers, L. J. Swartzendruber, Rev. Sci. Instr. 33, No. 5, 560-562 (Aug. 1961).

Proton magnetic resonance in clay minerals, R. L. Blaine, Highway Research Board Bull., No. 287, 44-55 (June 1962).

Spin-lattice relaxation in two rare earth double nitrates, R. P. Hudson and B. W. Mangum, Il Nuovo Cimento 23, 1133-1135 (Mar. 1962).

Dimensional changes in fibrous macromolecules: The system alpha-keratin-lithium bromide, L. Mandelkern, J. C. Halpin, A. F. Diorio, and A. S. Posner, Am. Chem. Soc. 34, No. 8, 1383-1391 (Apr. 1962).

Tchebycheff approximation by functions unisolvent of variable degree, J. R. Rice, Trans. Am. Math. Soc. 99, 298-302 (1961).

Best approximations and interpolating functions, J. R. Rice, Trans. Am. Math. Soc. 101, 477-498 (Dec. 1961).

The presence of singly-ionized gallium (Ga II) lines in stellar spectra, W. P. Bidelman and C. H. Corliss, Astrophys. J. 135, No. 3, 968-969 (May 1962).

Theory and biomedical applications of the analog computers, H. L. Mason, Natl. Inst. of Health Workshop on Biomedical Computing, No. 1 (July 1961).

Universal-time control of the arctic and antarctic F region, R. A. Duncan, J. Geophys. Research 6\%, 1823-1830 (May 1962).
Constitution diagram for $16 \% \mathrm{Cr}-2 \% \mathrm{Ni}$ stainless steel C. R. Johnson and S. J. Rosenberg, Trans. Quarterly Am. Soc. Metals 55, No. 2, 277-286 (June 1962).

Effect of surface roughness on the oxidation rate of iron, A. G. Eubanks, D. G. Moore, and W. A. Pennington, J. Electrochem. Soc. 109, No. 5, 382-389 (May 1962).

Evaluation of the nature of the surfaces of hard tooth tissues by a surface activity test, R. L. Bowen, Proc. Workshop on Adhesive Restorative Dental Materials (Indiana Univ., Bloomington, Indiana, Sept. 28-29, 1961).

Liquid drop collisions, O. G. Engel, Symp. Erosion and Cavitation, Am. Soc. Testing Materials Spec. Tech. Publ. No. 307, 3-16 (1961).

On the determination of disintegration rates by the coincidence method using high efficiency detectors, R. W. Hayward, Intern, J. Appl. Radiation and Isotopes 12, 148-150 (Dec. 1961).

Mass spectrometry, R. M. Reese, Anal. Chem. 34, No. 5, 243R-254R (Apr. 1962).

On the theory of diffraction grating interferometers, $H$. Mendlowitz and J. A. Simpson, J. Opt. Soc. Am. 52, No. 5, 520-524 (May 1962).

Effect of oleophobic films on fatigue crack propagation, W. L. Holshouser and H. P. Utech, Am. Soc. Testing Materials Proc., 61, 749 (1961).

Strange sounds in the atmosphere, Part II, R. K. Cook and J. M. Young, Sound-Its Uses and Control 1, No. 3, 25-33 (May-June 1962).

Fifteen years ACM, F. L. Alt, Commun. Assoc. Computing Machinery 5, No. 6, 300-307 (June 1962).

Scattered radiation from large cobalt-60 calibrating sources, L. Costrell, Health Phys. J. 8, No. 3, 261-272 (June 1962).

Measurement characteristics of the farm milk tank, M. W. Jensen, J. Milk and Food Technol. 25, No. 4, 112-115 (Apr. 1962).

The microwave Zeeman effect of free hydroxyl radicals: ${ }^{2} \mathrm{II}^{1} / 2$ levels, H. E. Radford, Phys. Rev. 126, 1035 (1962).

Second breakdown in transistors, H. A. Schafft and J. C. French, IRE Trans. Electron Devices ED-9, No. 2, 129 136 (July 1962).

Effect of noncrystallizable components on the crystallization kinetics of polymers, F. Gornick and L. Mandelkern, J. Appl. Phys. 33, No. 3, 907-913 (Mar. 1962).

Standards for plastics in the U.S.A., G. M. Kline, Proc. 13th Intern. Plastics Congress, p. 27-33 (Turin, Italy, Sept. 28-30, 1961).

Preservation of edge detail in metallography, W. P. Hayes, Jr., N. Tighe, and H. B. Kirkpatrick, Metal Progress 81, No. 3, 112 (Mar. 1962).

Traces of products of angular momentum matrices, I. Cartesian basis, E. Ambler, J. C. Eisenstein, and J. F. Schooley, J. Math. Phys. 3, No. 1, 118-130 (Jan.-Feb. 1962).

Measurement of linear photon polarization by pair production, L. C. Maximon and H. Olsen, Phys. Rev. 126, No. 1, 310-319 (Apr. 1962)

Standards for vinyl chloride plastics, F. W. Reinhart, Proc. SPE Regional Tech. Conf. "Vinyl Plastics" (New York, N.Y., Nov. 15, 1961); SPE J. 18, 308-311 (Mar. 1962).

Microsize magnetic field probes with axial symmetry, C. A. Shiffman, Rev. Sci. Instr. 33, No. 2, 206-207 (Feb. 1962).

Radiation hazards in realistic perspective, L. S. Taylor, Phys. Today 15, 32-38 (June 1962).

Stress-strain relationships in yarns subjected to rapid impact. loading. 9. Effect of yarn structure, J. C. Smith, J. M. Blandford, P. J. Shouse, and K. M. Towne, Textile Research J. 32, 472-480 (June 1962).

Device for chemically thinning crystals for transmission electron microscopy, H. B. Kirkpatrick and S. Amelinckx, Rev. Sci. Instr. 33, No. 4, 488-489 (Apr. 1962).

Signs of nuclear resonance coupling constants in saturated aliphatic systems, H. Finegold, Proc. Chem. Soc. (London, England) No. 6 (June 1962). 
Stress corrosion of high strength cast aluminum alloys, F. M. Reinhart and W. F. Gerhold, Corrosion 18, No. 4, 158 (Apr. 1962)

Fluorescence in comets as a Markov process, T. Carrington, Astrophys. J. 135, No. 3, 883-891 (May 1962)

Digital pattern recognition by moments, F. L. Alt, J. Assoc. Computing Mach. 9, No. 2, 240-258 (Apr. 1962).

The nuclear photoeffect in holmium and erbium, E. G. Fuller and E. Hayward, Nuclear Phys. 30, 613-635 (1962).

Phase-modulated calibrator for testing phase meters, M. C. Thompson, Jr., Rev. Sci. Instr. 33, 563-564 (May 1962).
*Publications for which a price is indicated (except for Technical Notes) are available only from the Superintendent of Documents, U.S. Government Printing Office, Washington 25, D.C. (foreign postage, one-fourth additional). Technical Notes are available only from the Office of Technical Services, U.S. Department of Commerce, Washington 25, D.C. (order by PB number). Reprints from outside journals and the NBS Journal of Research may often be obtained directly from the authors. 